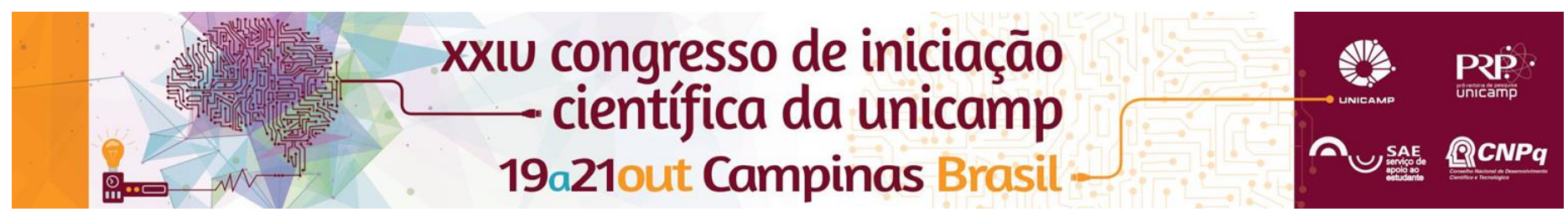

\title{
Síntese e caracterização de nanofios do composto férmion pesado Celn $_{3}$
}

\author{
Caique C. Rodrigues*, Dina Tobia, Karoline O. Moura, Camilo B. R. Jesus, Kleber R. Pirota, Pascoal J. G. \\ Pagliuso
}

\section{Resumo}

Estamos aqui propondo a síntese e a caracterização de nanofios de Celn3 através da técnica de nanonucleação por fluxo metálico (NNFM). O objetivo deste projeto é estabelecer as rotas de síntese de nanofios de Celn3, controlando o diâmetro entre $20 \mathrm{~nm}$ e $500 \mathrm{~nm}$ e caracteriza-los por medidas de susceptibilidade magnética, calor específico, microscopia (TEM), NMR e difração de elétrons para que se possa relacionar os efeitos da variação da dimensionalidade do sistema com suas propriedades físicas.

\section{Palavras-chave: \\ Nanofio, Supercondutor, Magnetismo.}

\section{Introdução}

O estudo do papel da dimensionalidade nas propriedades físicas de sistemas como o $\mathrm{Celn}_{3}$ ganhou nova perspectiva com o desenvolvimento de um método de produção de nanofios denominado técnica de nanonucleação por fluxo metálico (NNFM) ${ }^{1}$. A partidos dos resultados obtidos em amostras monocristalinas (sistema massivos tridimensionais), pretendemos estender esta análise à sistemas de nanofios monocristalinas (sistemas unidimensionais).

Devido à flexibilidade do composto para se fazer dopagem e/ou substituição nos diferentes sítios cristalográficos, este sistema é uma excelente oportunidade para estudar de forma sistemática o efeito RKKY, a dimensionalidade nas interações no efeito Kondo, a criticalidade quântica e, particularmente, obter um melhor entendimento na inter-relação entre magnetismo e supercondutividade não convencional em sistemas de férmions pesados ${ }^{2}$.

\section{Resultados e Discussão}

Para sintetizar os nanofios utilizamos como substrato membranas de alumina porosa $\left(\mathrm{Al}_{2} \mathrm{O}_{3}\right)$. Durante este tempo foi discutido quais as melhores rotas de se produzir tais membranas pois pode-se dizer que a obtenção de nanofios depende quase que unicamente delas.

O método utilizado para se produzir as membranas se chama "Hard Anodization". Após muita discussão sobre como poderíamos otimizar o processo de produção e testar fatores importantes da membrana como, por exemplo, variar o diâmetro dos poros, foi possível decidir uma metodologia fixa e sistemática.

Com as membranas prontas pudemos começar então as primeiras tentativas de nucleação de nanofios através da técnica NNFM. Foi colocado sobre a melhor membrana que tínhamos $0,4037 \mathrm{~g}$ de Cério e $3,3081 \mathrm{~g}$ de Índio e o sistema foi levado para o forno para que se começasse a difusão dos metais para dentro dos poros.

Após todo o processo o resultado foi positivo e, como pode ser visto na Figura 1, houve nucleação de nanofios de Celn ${ }_{3}$.

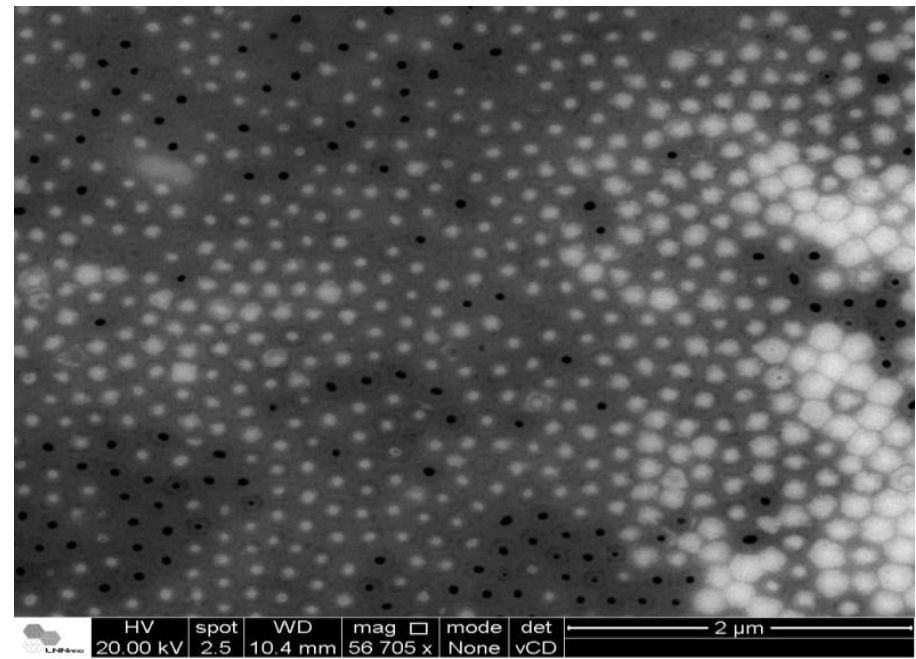

Figura 1. Imagem obtida por microscopia eletrônica de transmissão (TEM) de nanofios nucleados nos poros de uma membrana porosa de alumina.

\section{Conclusão}

Nós tivemos sucesso na obtenção de nanofios de Celn ${ }_{3}$ com diâmetros controlado entre $50 \mathrm{~nm}$ e $100 \mathrm{~nm}$. Os próximos passos para este projeto consistem na obtenção de dados que caracterizem o sistema, tais como a suscetibilidade magnética e o calor específico, e na criação de técnicas para que se consigam membranas com diâmetros maiores do que $100 \mathrm{~nm}$.

\section{Agradecimentos}

Gostaria de agradecer a FAPESP e a Unicamp pelo apoio financeiro e pela excelente oportunidade de estudos como estes.

\footnotetext{
${ }^{1}$ Pirota, K. R. et al. Processo de produção de nanofios monocristalinos intermetálicos. BR patent 1020140197940 issued 11 Aug. 2014

${ }^{2}$ G.R. Stewart, Reviews of Modern Physics 74 (4): 797-855 OCT 2011

${ }^{3}$ W. Lee, R. Ji, U. Gösele, K. Nielsch, Fast fabrication of long-range ordered porous alumina membranes by hard anodization. Nat. Mater. 5, 741-747 (2006)
} 